\title{
Childhood Brain Germinoma
}

National Cancer Institute

\section{Source}

National Cancer Institute. Childhood Brain Germinoma. NCI Thesaurus. Code C6207.

A germinoma arising from the brain during childhood. 